\title{
Prediksi E-Wom dan Subjective Norm terhadap Purchase Intention: Brand Attitude Sebagai Variabel Mediasi
}

\author{
Leonardo Tan dan Keni \\ Program Studi Manajemen Fakultas Ekonomi \& Bisnis \\ Universitas Tarumanagara \\ Email: Leonardo.115160293@stu.untar.ac.id
}

\begin{abstract}
The purpose of this paper is to examine whether 1) E-WOM and subjective norm can predict purchase intention 2) E-WOM and subjective norm can predict brand attitude 3) brand attitude can predict purchase intention 4) brand attitude mediates the prediction EWOM and subjective norm on purchase intention. The conceptual model and the analysis of related hypotheses were based on a convenience sampling of one of bubble tea brand's consumers based in Jakarta. The data were collected using quetionnaire. In total, 153 participants responded to the survey. Structural equation modelling (SEM), specifically partial least square (PLS) was employed to analyze the data. The results indicate that EWOM and subjective norm are positive and significant predictors towards brand attitude. EWOM and brand attitude are positive and significant predictors towards purchase intention. brand attitude is positive and significant mediate E-WOM and subjective norm towards purchase intention. While subjective norm is negative and significant predictors towards purchase intention. Theoretical and practical contributions are discussed.
\end{abstract}

Keywords: E-WOM, subjective norm, brand attitude, purchase intention

Abstrak: Tujuan dari penelitian ini adalah untuk menguji apakah 1) E-WOM dan subjective norm dapat memprediksi purchase intention 2) E-WOM dan subjective norm dapat memprediksi brand attitude 3) brand attitude dapat memprediksi purchase intention 4) brand attitude dapat memediasi prediksi E-WOM dan subjective norm terhadap purchase intention. Penelitian ini menggunakan metode convenience sampling terhadap konsumen salah satu merek minuman boba yang berdomisili di Jakarta. Data dikumpulkan menggunakan kuesioner dan data yang terkumpul sebanyak 153 responden. Teknik analisis data yang digunakan dalam penelitian ini yaitu menggunakan structural equation modelling (SEM), tepatnya yaitu partial least square (PLS). Hasil dari penelitian ini menunjukkan bahwa $E$ WOM dan subjective norm memprediksi secara positif dan signifikan terhadap brand attitude. E-WOM dan brand attitude memprediksi secara positif dan signifikan terhadap purchase intention. brand attitude memediasi prediksi E-WOM dan subjective norm terhadap purchase intention secara positif dan signifikan, sedangkan subjective norm memprediksi secara signifikan dan negatif terhadap purchase intention. Kontribusi teoritikal dan praktikal juga dibahas dalam penelitian ini.

Kata kunci: E-WOM, norma subjektif, sikap merek, niat pembelian

\section{LATAR BELAKANG}

Indonesia memiliki prospek industri Food and Beverage yang positif. Kementerian perindustrian memproyeksikan pertumbuhan industri Food and Beverage akan mencapai 9 persen di tahun 2019 jika realisasi investasi mencapai Rp 63 triliun (Thejakartapost, 2019). Terdapat salah satu minuman boba yang sedang naik daun di Indonesia. Salah satu minuman 
boba tersebut memasuki Indonesia dan membuka gerai pertamanya di Jakarta pada awal Juni 2019. Untuk dapat mencoba minuman ini pun, konsumennya bisa mengantri sampai dua jam. Di Jakarta sendiri juga memiliki banyak gerai boba. Oleh sebab itu minuman boba harus tetap mempertahankan kualitas dari produknya dan meningkatkan teknik pemasaran untuk meningkatkan purchase intention konsumen.

Menurut Yan (2011), purchase intention dapat didefinisikan sebagai momen dimana konsumen telah membuat keputusan tentang produk apa yang akan dibeli. Berdasarkan penelitian terdahulu, terdapat banyak faktor yang mempengaruhi purchase intention. Khan dan Azam (2016) mengaitkan purchase intention dengan attitude, subjective norm, perceived behavioral control, dan religiosity. Penelitian Pool dan Najafabadi (2015) menekankan bahwa purchase intention dapat dijelaskan oleh brand image dan wom. Lebih lanjut hasil penelitian Poulis dan Rizomyliotis (2018) menunjukkan brand loyalty, brand awareness, dan ewom secara signifikan mempengaruhi purchase intention. Hasil penelitian Kudeshia dan Kumar (2016) menyatakan bahwa terdapat hubungan positif ewom terhadap purchase intention. Byon et al. (2014) menyatakan bahwa subjective norm mempengaruhi purchase intention secara positif. Hasil penelitian Kudeshia dan Kumar (2016) menyatakan bahwa brand attitude secara signifikan mempengaruhi purchase intention dan juga hasil penelitian menemukan bahwa brand attitude memediasi secara parsial pengaruh ewom terhadap purchase intention. Lebih lanjut, penelitian Garg dan Joshi (2018) menyatakan bahwa attitude secara signifikan memediasi hubungan antara subjective norm dan purchase intention.

Walaupun sebelumnya sudah ada penelitian-penelitian mengenai purchase intention, EWOM, subjective norm, dan brand attitude, peneliti menemukan bahwa hasil penelitian sebelumnya masih ada yang kontradiktif antara satu penelitian dengan penelitian lain. Hasil penelitian ini diharapkan dapat membantu para marketing manager mengetahui faktor-faktor yang mempengaruhi niat pembelian konsumen, sehingga hal tersebut dapat meningkatkan penjualan dan dapat bersaing dengan gerai boba lain.

\section{KAJIAN TEORI}

Theory of Reasoned Action (TRA) yang dikemukakan oleh Fishbein dan Azjen (1975), menjelaskan bahwa tindakan yang dilakukan seseorang didasarkan pada niat perilaku orang tersebut, dimana niat perilaku ini merupakan fungsi dari sikap terhadap perilaku dan norma subjektif. Teori ini menjelaskan niat perilaku seseorang dibentuk oleh sikap terhadap perilaku dan norma subjektif. Sikap terhadap perilaku menjelaskan apakah seseorang mendukung atau menentang keterlibatan dalam perilaku, kemudian norma subjektif menjelaskan persepsi orang tentang tekanan sosial terhadap melakukan atau tidak perilaku tersebut.

Theory of Planned Behaviour (TPB) merupakan teori yang nyatakan oleh Ajzen (1991). Teori in merupakan pengembangan dari Theory of Reasoned Action (TRA), dimana pada teori ini terdapat penambahan faktor perceived behavioral control, karena umumnya seseorang mengambil tindakan berdasarkan informasi yang diterima terlebih dahulu. Theory of Planned Behaviour (TPB) menjelaskan niat perilaku seseorang dibentuk melalui 3 faktor yaitu sikap, norma subjektif dan kontrol perilaku. Kontrol perilaku menjelaskan kemudahan atau kesulitan dalam menampilkan perilaku.

Purchase Intention. Menurut Tariq et al. (2013: 340) purchase intention adalah "The implied promise to one's self to buy the product again whenever one makes the next trip to the market". Kemudian menurut Garg dan Joshi (2018: 686), "Purchase intention refers to the mental stage in the decision-making process where the consumer has developed an actual willingness to act toward an object or brand." Selain itu, Borzooei dan Asgari (2014: 17) 
menyatakan "Purchase intention is also the extensive attention of consumers towards the specific brand." Berdasarkan penjelasan definisi purchase intention di atas, peneliti menyimpulkan bahwa niat pembelian konsumen merupakan keputusan yang diambil oleh konsumen untuk membeli kembali suatu produk ketika konsumen kembali ke pasar.

E-WOM. Menurut Henning-Thurau et al. (2004: 39) ewom dapat didefinisikan sebagai "... any positive or negative statement made by a potential, actual, or former customer about a product or a company, available to a multitude of people and institutions via the internet." Kemudian menurut Abubakar, Ilkan dan Sahin (2016: 694) ewom adalah: "an informal network that possesses the primary part of the social influence model." Lebih lanjut dalam penelitian Jalilvand dan Samiei (2012: 594) menyatakan ewom sebagai "All informal communications directed at consumers through internet-based technology related to the usage or characteristics of particular goods and services, or their sellers." Berdasarkan penjelasan definisi ewom di atas, peneliti menyimpulkan bahwa ewom merupakan pernyataan positif atau negatif dari konsumen mengenai suatu produk atau jasa, dimana pernyataan tersebut disampaikan melalui internet.

Subjective Norm. Menurut Elseidi (2017: 172), subjective norm merupakan "subjective norms are considered a function of salient normative beliefs, concerned with the likelihood that specific individuals or groups approve or disapprove of performing a particular behaviour by related groups, such as the expectations of friends, peers and other family members, and their motivation of complying with these referents." Sementara subjective norm menurut Mukhtar dan Butt (2012: 113), "subjective norms also referred to as normative norms, are a function of beliefs that specify an individual's thinking about the acceptability of a particular behaviour by related groups." Byon et al. (2014: 160) menyatakan subjective norm sebagai "The level of perceived social pressures set by significant others that influence one's behavior." Berdasarkan definisi subjective norm di atas, peneliti menyimpulkan bahwa subjective norm merupakan suatu pemikiran yang mempengaruhi tindakan seseorang, dimana pemikiran tersebut bergantung pada pemikiran dan persetujuan orang sekitarnya atau lingkungan sosialnya.

Brand Attitude. Menurut Kudeshia dan Kumar (2016: 315), brand attitude dapat di definisikan sebagai "Consumer's overall evaluation of a brand." Selanjutnya, Ajzen (1991: 188) mendefinisikan attitude sebagai "The degree to which a person has a favorable or an unfavorable evaluation of a behavior in question." Fishbein dan Ajzen (1975: 11) mengatakan bahwa attitude adalah "The amount of affect for or against some object." Berdasarkan definisi brand attitude di atas, peneliti menyimpulkan bahwa brand attitude merupakan evaluasi suatu merek produk oleh konsumen, dimana hasil evaluasi tersebut dapat menghasilkan sikap yang positif atau negatif terhadap suatu merek.

Kaitan antara $\boldsymbol{e}$-wom dan purchase intention. Banyak orang yang membaca ulasan orang mengenai suatu produk atau jasa sebelum membeli atau menggunakan produk atau jasa tersebut. Park et al. (2007), yang menjelaskan ulasan bertindak sebagai informan dan juga secara signifikan mempengaruhi purchase intention dan actual purchase. Penelitian Lopez dan Sicilia (2014), mengatakan bahwa E-WOM secara signifikan mempengaruhi keputusan pembelian. Hasil penelitian tersebut sejalan dengan penelitian Themba et al. (2013), menghasilkan bahwa mahasiswa biasanya akan mencari opini melalui ewom dan hal tersebut secara positif mempengaruhi purchase intention.

Berdasarkan pemaparan di atas, maka hipotesis dalam penelitian ini adalah sebagai berikut.

$\mathrm{H}_{1 \mathrm{a}}:$ EWOM dapat memprediksi secara positif purchase intention 
Kaitan antara subjective norm dan purchase intention. Subjective norm merupakan salah satu komponen penting dalam mengevaluasi niat pembelian dari konsumen. Menurut Lutz (1991), subjective norm dapat mempengaruhi niat pembelian untuk memilih produk-produk tersebut. Kemudian menurut Al-Nahdi et al. (2008), juga mengatakan bahwa subjective norm diamati sebagai variabel yang signifikan yang mempengaruhi niat beli produk makanan "halal". Selain itu, Norazah dan Abang (2016) mengatakan bahwa kelompok referensi mempengaruh niat pembelian konsumen, sehingga konsumen mengantisipasi pandangannya terhadap kelompok referensi agar tidak salah mengambil keputusan pembelian.

Berdasarkan pemaparan di atas, maka hipotesis dalam penelitian ini adalah sebagai berikut.

$\mathrm{H}_{1 \mathrm{~b}}$ : Subjective norm dapat memprediksi secara positif purchase intention

Kaitan antara ewom dan brand attitude. Penelitian Wu dan Wang (2011), menjelaskan bahwa ewom dengan sumber kredibilitas yang lebih tinggi, menunjukkan sikap terhadap merek yang lebih unggul dibanding sumber dengan kredibilitas yang lebih rendah. Menurut penelitian Ying dan Chung (2007), ewom yang positif mengarah ke sikap yang lebih menguntungkan terhadap produk tertentu dibanding ewom yang negatif. Penjelasan diatas sejalan dengan penelitian yang dilakukan oleh Kudeshia dan Kumar (2016), yang menjelaskan bahwa ewom berpengaruh positif dan signifikan terhadap brand attitude.

Berdasarkan pemaparan di atas, maka hipotesis dalam penelitian ini adalah sebagai berikut.

$\mathrm{H}_{2 \mathrm{a}}$ : EWOM dapat memprediksi secara positif brand attitude

Kaitan antara subjective norm dan brand attitude. Sikap seseorang terhadap suatu merek dapat dipengaruhi oleh pendapat atau saran yang diberikan oleh orang lain yang ada di lingkungan sosialnya. Hal ini sesuai dengan penelitian Miniard dan Cohen (1983), yang menyatakan terhadap ketergantungan antara subjective norm dan brand attitude. Kemudian penelitian oleh Ryan (1982), menyatakan bahwa sikap dapat dipengaruhi oleh kepercayaan normatif atau norma subjektif. Kemudian berdasarkan hasil penelitian Paul et al. (2016), menyatakan hubungan yang positif antara subjective norm dan attitude.

Berdasarkan pemaparan di atas, maka hipotesis dalam penelitian ini adalah sebagai berikut.

$\mathrm{H}_{2 \mathrm{~b}}$ : Subjective norm dapat memprediksi secara positif brand attitude

Kaitan antara Brand Attitude dan Purchase Intention. Menurut Keller dan Lehman (2006), jika konsumen memiliki sikap yang positif terhadap suatu merek, hal itu secara signifikan mempengaruhi tujuan pembelian dan kesiapannya untuk membayar nilai premium. Hal ini sejalan dengan beberapa penelitian yang dilakukan oleh Mukhtar dan Mohsin Butt (2012), yang mengatakan bahwa purchase intention untuk membeli merek "halal" secara positif dan signifikan terkait dengan attitude. Kemudian menurut penelitian Dodds et al. (1991), sikap merek memiliki dampak positif pada niat beli.

Berdasarkan pemaparan di atas, maka hipotesis dalam penelitian ini adalah sebagai berikut.

$\mathrm{H}_{3}$ : Brand attitude dapat memprediksi secara positif purchase intention

Brand attitude memediasi kaitan antara ewom dan purchase intention. Dalam penelitian yang dilakukan oleh Kudesia dan Kumar (2016), menghasilkan bahwa brand attitude memediasi hubungan antara E-WOM dan purchase intention secara parsial. Sementara menurut Prendergast et al. (2010), sikap positif konsumen terhadap informasi E-WOM di forum online akan memperkuat nilai pembelian konsumen dan juga menurut penelitian Erkan dan Evans (2016) menunjukkan bahwa sikap yang positif yang dibentuk konsumen terhadap informasi $E$-WOM di media sosial memiliki efek positif pada niat pembelian.

Berdasarkan pemaparan di atas, maka hipotesis dalam penelitian ini adalah sebagai berikut.

$\mathrm{H}_{4 \mathrm{a}}$ : Brand attitude dapat memediasi prediksi E-WOM terhadap purchase intention 
Brand attitude memediasi kaitan antara Subjective norm dan Purchase intention. Menurut Ajzen (1988), sikap merupakan bagian penting dalam mendeskripsikan perilaku manusia, dimana perilaku seseorang dapat mempengaruhi orang disekitar dalam melakukan pembelian. Hal ini sesuai dengan penelitian yang dilakukan oleh Bananuka et al. (2019), yang menyatakan bahwa attitude secara signifikan memediasi hubungan antara subjective norm dan intention.

Berdasarkan pemaparan di atas, maka hipotesis dalam penelitian ini adalah sebagai berikut. $\mathrm{H}_{4 \mathrm{~b}}$ : Brand attitude dapat memediasi prediksi subjective norm terhadap purchase intention

Berdasarkan uraian kaitan antar variabel di atas, maka model penelitian yang digunakan dalam penelitian ini adalah sebagai berikut:

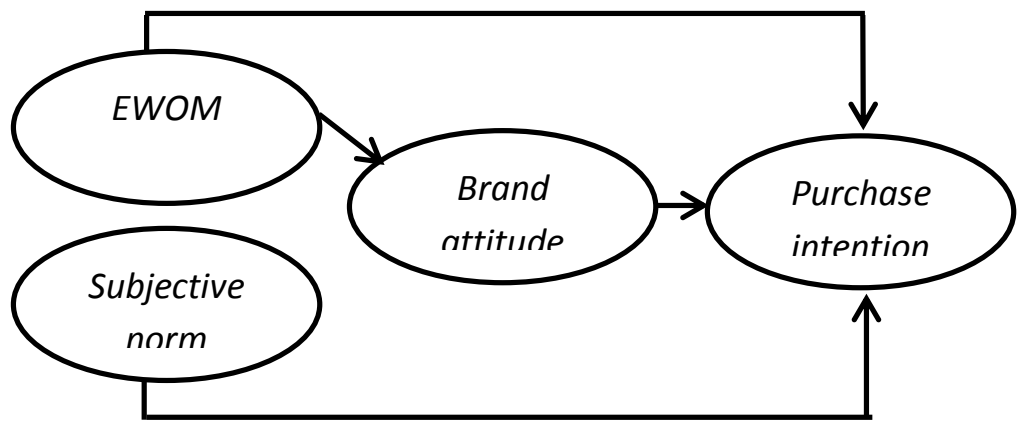

Gambar 1. Model Penelitian

\section{METODOLOGI}

Penelitian ini merupakan penelitian deskriptif cross sectional. Populasi yang digunakan adalah konsumen salah satu merek minuman boba di wilayah Jakarta. Sampel diambil menggunakan metode nonprobability sampling, tepatnya dengan menggunakan teknik convenience sampling. Hal ini dilakukan agar pengumpulan data dapat dilakukan dengan mudah dan cepat. Jumlah responden yang diambil oleh peneliti sebanyak 153 responden.

Pengukuran variabel-variabel dalam penelitian ini mengacu pada penelitian sebelumnya antara lain sebagai berikut:

\begin{tabular}{|l|c|l|}
\hline \multicolumn{1}{|c|}{ Variabel } & Item & \multicolumn{1}{|c|}{ Sumber } \\
\hline $\begin{array}{l}\text { Purchase } \\
\text { Intention }\end{array}$ & 3 & $\begin{array}{l}\text { Schivinski dan } \\
\text { Dabrowski, } \\
(2014) ; \text { Yoo et al. } \\
\end{array}$ \\
& & $\begin{array}{l}(2000) \text { Shukla } \\
(2011) ; \text { Khan dan } \\
\text { Azam (2016) }\end{array}$ \\
\hline E-WOM & 4 & $\begin{array}{l}\text { Bambauer-Sachse } \\
\text { dan Mangold, } \\
(2011) ; \text { Jalilvand } \\
\text { dan Samiei (2012) }\end{array}$ \\
& \\
\hline
\end{tabular}

\begin{tabular}{|c|c|c|}
\hline Variabel & Item & Sumber \\
\hline Subjective Norm & 5 & $\begin{array}{lrr}\text { Lada } & \text { et } \quad \text { al. } \\
(2009) ; & \text { Bansal } \\
\text { dan } & \text { Taylor } \\
(2002) & \end{array}$ \\
\hline Brand Attitude & 4 & $\begin{array}{l}\text { Schivinski dan } \\
\text { Dabrowski } \\
\text { (2014); Tang et } \\
\text { al. (2011); Khan } \\
\text { dan Azam } \\
(2016)\end{array}$ \\
\hline
\end{tabular}




\section{HASIL UJI STATISTIK}

Analisis validitas, baik convergent validity maupun discriminant validity, telah dilakukan dengan menggunakan analisis average variance extracted, loading factors, Fornell-Larcker dan cross loadings. Hasilnya seluruh variabel dan indikator dalam penelitian ini valid untuk digunakan. Keempat variabel yang digunakan dalam penelitian ini juga dinyatakan reliabel, karena memiliki nilai composite reliability diatas 0,70 (Garson, 2016) dan nilai cronbach's alpha diatas 0,60 (Hussein, 2015).

$\mathrm{R}^{2}$ digunakan untuk mengukur seberapa besar variabel $E$-WOM, subjective norm, dan brand attitude dapat menjelaskan variabel purchase intention. $R$ square sebesar 0,548 menjelaskan bahwa sebesar $54,8 \%$ dari variabel mediasi yaitu brand attitude dapat dijelaskan oleh variabel dalam penelitian ini, sisanya sebesar $45,2 \%$ dapat dijelaskan oleh variabelvariabel lain yang tidak diteliti dalam penelitian ini. Selanjutnya sebesar 0,560 nilai $R$ square dari purchase intention menjelaskan bahwa sebesar 56,0\% dari variabel purchase intention dapat dijelaskan oleh variabel dalam penelitian ini, sisanya sebesar $44 \%$ dapat dijelaskan oleh variabel-variabel lain yang tidak diteliti dalam penelitian ini. Berdasarkan hasil pengujian di atas dapat disimpulkan bahwa nilai $R$-Square dalam penelitian ini tergolong moderate (Hair et al., 2011). Selanjutnya, hasil pengujian $\mathrm{Q}^{2}$ menunjukan nilai sebesar 0,329 untuk brand attitude dan 0,369 untuk purchase intention yang artinya nilai predictive relevance $\left(\mathrm{Q}^{2}\right)$ dalam penelitian ini lebih besar dari 0 (nol).

Hasil analisis data secara singkat dapat dilihat pada Tabel 1.

Tabel 1. Hasil Pengujian Hipotesis

\begin{tabular}{lccc}
\multicolumn{1}{c}{ Variabel } & Path Coefficient & t-statistics & p-values \\
\hline Brand attitude => Purchase intention & 0,567 & 5,748 & 0,000 \\
\hline E-WOM => Brand attitude & 0,280 & 2,492 & 0,013 \\
\hline E-WOM => Purchase intention & 0,437 & 3,746 & 0,000 \\
\hline Subjective norm => Brand attitude & 0,504 & 5,037 & 0,000 \\
\hline $\begin{array}{l}\text { Subjective norm => Purchase intention } \\
\begin{array}{l}\text { E-WOM }=>\text { Brand attitude => Purchase } \\
\text { intention }\end{array}\end{array}$ & $-0,225$ & 2,231 & 0,026 \\
\hline $\begin{array}{l}\text { Subjective norm }=>\text { Brand attitude => } \\
\text { Purchase intention }\end{array}$ & 0,159 & 2,158 & 0,031 \\
\hline
\end{tabular}

Berdasarkan hasil pengujian bootstrapping pada Tabel 1 di atas, maka dapat disimpulkan dua persamaan. Persamaan yang pertama yaitu persamaan purchase intention yang dijelaskan melalui: $\mathrm{PI}=0,567 \mathrm{BA}+0,437 E W O M-0,225 \mathrm{SN}$.

Berdasarkan persamaan di atas, dapat dijelaskan bahwa variabel brand attitude merupakan prediktor terbesar purchase intention yaitu sebesar 0,567 dan dilanjutkan oleh EWOM yang memprediksi purchase intention yaitu sebesar 0,437 dan juga yang terakhir subjective norm memprediksi secara negatif purchase intention yaitu sebesar -0,225.

Selanjutnya persamaan kedua yaitu persamaan brand attitude. Berikut persamaan brand attitude dijelaskan di bawah ini: $\mathrm{BA}=0,280 E W O M+0,504 \mathrm{SN}+e$

Berdasarkan persamaan tersebut, dapat dilihat bahwa subjective norm merupakan prediktor terbesar brand attitude dan merupakan prediktor positif yaitu sebesar 0,504, selanjutnya E-WOM memprediksi brand attitude secara positif yaitu sebesar 0,280. Dari kedua persamaan tersebut dapat disimpulkan bahwa subjective norm merupakan prediktor terbesar brand attitude dan brand attitude merupakan prediktor terbesar terhadap purchase intention dalam penelitian ini. 
Pengujian effect size juga dilakukan. Hasilnya menunjukan bahwa variabel subjective norm memiliki efek perubahan yang besar terhadap brand attitude yaitu sebesar 0,233, dan efek yang rendah terhadap purchase intention sebesar 0,039. Selanjutnya, variabel E-WOM memiliki efek yang rendah terhadap brand attitude sebesar 0,072 dan memiliki efek yang sedang terhadap purchase intention sebesar 0,168. Terakhir, variabel brand attitude memiliki efek yang besar terhadap variabel purchase intention sebesar 0,331. Selain itu, dilakukan pula pengujian goodness of fit $(\mathrm{GoF})$. Hasil perhitungan menunjukan hasil yang menyatakan model yang digunakan dalam penelitian ini memiliki nilai GoF sebesar 0,5929. Model dalam penelitian ini memiliki kecocokan atau tergolong besar 0,5929 (>0,36) (Wetzels et al., 2009)

\section{DISKUSI}

Berdasarkan hasil pengujian hipotesis pertama $\left(\mathrm{H}_{1}\right)$, dimana terdapat dua sub bagian dalam hipotesis pertama ini. Pertama $\mathrm{H}_{1 \mathrm{a}}$, menunjukkan bahwa EWOM dapat memprediksi secara positif terhadap purchase intention. Sehingga dapat disimpulkan $\mathrm{H}_{1 a}$ tidak ditolak. Hasil dari pengujian tersebut sesuai dengan beberapa penelitian yang sebelumnya telah dilakukan, salah satunya yaitu penelitian Park et al. (2007). Menurut park et al. (2007), ulasan bertindak sebagai informan dan juga secara signifikan mempengaruhi purchase intention dan actual purchase. Ulasan yang diberikan oleh konsumen dapat berupa ulasan positif maupun negatif, hal tersebut tergantung pada evaluasi yang dilakukan oleh konsumen. Banyaknya konsumen yang membeli suatu brand minuman boba, kemudian melakukan postingan dan memberikan ulasan mengenai brand ini membuat calon konsumen penasaran dengan produk ini. Ditambah lagi panjangnya antrian suatu brand minuman boba sempat viral di internet membuat niat pembelian konsumen semakin meningkat. Selanjutnya $\mathrm{H}_{1 b}$ ditolak, karena subjective norm memprediksi secara negatif terhadap purchase intention. Hal tersebut dapat dilihat melalui hasil pengujian path coefficient. Hal ini berbanding terbalik dengan penelitian yang dilakukan oleh Al-Nahdi et al. (2008) yang mengatakan subjective norm diamati sebagai variabel yang signifikan dan positif mempengaruhi niat beli produk. Hasil hipotesis ini menunjukkan bahwa semakin besar pengaruh pemikiran orang sekitar terhadap produk suatu brand minuman boba maka hal tersebut menyebabkan semakin berkurangnya niat pembelian konsumen terhadap suatu brand minuman boba. Banyaknya produk sejenis yang bermunculan di pasar membuat konsumen penasaran untuk mencoba produk lain yang sejenis agar dapat membandingkannya dengan suatu brand minuman boba.

Selanjutnya, hipotesis kedua $\left(\mathrm{H}_{2}\right)$ juga memiliki dua sub hipotesis. Pertama $\mathrm{H}_{2 \mathrm{a}}$, EWOM dapat memprediksi secara positif sehingga dapat disimpulkan bahwa $\mathrm{H}_{2 \mathrm{a}}$ tidak ditolak. Hasil penelitian ini sesuai dengan penelitian yang dilakukan oleh Kudeshia dan Kumar (2016) yang menjelaskan bahwa EWOM berpengaruh positif dan signifikan terhadap brand attitude. Sikap positif terhadap suatu brand minuman boba dapat terbentuk jika konsumen memberikan ulasan yang positif mengenai suatu brand minuman boba. Selanjutnya $\mathrm{H}_{2 \mathrm{~b}}$, subjective norm dapat memprediksi secara positif brand attitude sehingga $\mathrm{H}_{2 \mathrm{~b}}$ tidak ditolak. Hasil penelitian ini sesuai dengan pendapat yang dikemukakan oleh Paul et al. (2016) bahwa subjective norm dan attitude memiliki hubungan yang positif. Orang-orang disekitar konsumen yang mengatakan hal positif yang berkaitan dengan suatu brand minuman boba, hal tersebut akan mempengaruhi sikap konsumen terhadap suatu brand minuman boba menjadi baik dan juga sebaliknya.

Pada pengujian hipotesis ketiga $\left(\mathrm{H}_{3}\right)$, terlihat bahwa brand attitude terbukti dapat memprediksi secara positif purchase intention sehingga dinyatakan $\mathrm{H}_{3}$ tidak ditolak. Hal ini sejalan dengan penelitian yang dilakuakan oleh Mukhtar dan Mohsin Butt (2012), yang mengatakan purchase intention secara positif dan signifikan terkait dengan attitude. Berdasarkan hasil penilaian responden yaitu kualitas bubblenya yang lebih tinggi merupakan 
suatu nilai tambah perusahaan dalam meningkatkan niat pembelian konsumen. Untuk dapat bersaing dengan perusahaan lain, brand ini harus menciptakan sikap konsumen yang positif terhadap perusahaan, karena hal tersebut merupakan faktor penting dalam meningkatkan niat pembelian konsumen.

Lebih lanjut, hipotesis terakhir yaitu hipotesis keempat $\left(\mathrm{H}_{4}\right)$ memiliki dua sub hipotesis. Hipotesis pertama $\mathrm{H}_{4 \mathrm{a}}$, brand attitude terbukti dapat memprediksi secara positif mediasi hubungan antara EWOM terhadap purchase intention sehingga hipotesis ini tidak ditolak. Hal ini sejalan dengan penelitian yang dilakukan oleh Kudeshia dan Kumar (2016), yang menyatakan bahwa brand attitude memediasi hubungan antara EWOM dan purchase intention secara parsial. Sikap yang positif terhadap suatu merek akan terbentuk ketika terdapat ulasan yang positif mengenai merek tersebut. Ketika masyarakat memiliki sikap yang positif terhadap suatu brand minuman boba melalui ulasan positif yang diberikan oleh orang lain, maka niat pembelian konsumen terhadap suatu brand minuman boba akan meningkat. Terakhir $\mathrm{H}_{4 \mathrm{~b}}$, subjective norm terbukti dapat memprediksi secara positif mediasi hubungan antara subjective norm terhadap purchase intention sehingga hipotesis $\mathrm{H}_{4 \mathrm{~b}}$ tidak ditolak. Penelitian yang dilakukan oleh Bananuka et al. (2019) sesuai dengan penelitian ini, yang mengatakan bahwa attitude secara signifikan memediasi hubungan antara subjective norm dan intention. Perilaku atau pemikiran orang yang ada disekitar konsumen dapat mempengaruhi sikap konsumen terhadap suatu merek. Ketika masyarakat memiliki sikap yang positif mengenai suatu brand minuman boba melalui perilaku dan pemikiran orang disekitar konsumen, maka hal tersebut akan meningkatkan niat pembelian konsumen.

\section{KESIMPULAN DAN SARAN}

Dari hasil uraian dan analisis yang telah dilakukan, dapat dilihat bahwa $E$-WOM dan brand attitude dapat memprediksi secara positif dan signifikan terhadap purchase intention suatu brand minuman boba, E-WOM dan subjective norm dapat memprediksi secara positif dan signifikan terhadap brand attitude suatu brand minuman boba, brand attitude dapat memediasi prediksi E-WOM dan subjective norm terhadap purchase intention suatu brand minuman boba, dan terakhir subjective norm memprediksi secara negatif dan signifikan terhadap purchase intention suatu brand minuman boba. Peneliti menyarankan suatu brand minuman boba untuk terus menyenangkan konsumen dengan produk dan layanan yang diberikan kepada konsumen. Kedua, peneliti menyarankan suatu brand minuman boba untuk terus memberikan kesan baik kepada konsumennya. Untuk penelitian selanjutnya, disarankan agar memperluas jangkauan pengambilan sampel dan wilayah yang dicakupi, sehingga menghasilkan karakteristik yang berbeda yang dapat memperkuat dan melengkapi penelitian sebelumnya. Terakhir, penelitian selanjutnya disarankan untuk menambah dan mengembangkan variabel-variabel lain yang belum dilakukan oleh penelitian sebelumnya, dimana variabel-variabel tersebut dapat memprediksi purchase intention dengan lebih baik lagi. Sebagai contoh seperti variabel customer satisfaction, brand loyalty, brand trust, dan service quality.

\section{DAFTAR PUSTAKA}

Abubakar, A. M., Ilkan, M., \& Sahin, P. (2016). eWOM, eReferral and gender in the virtual community. Marketing Intelligence \& Planning, 34(5), 692-710.

Ajzen, I. (1988). Attitudes, personality, and behavior. Homewood, IL, US. Dorsey Press. http://dx. doi. org/10.1148/radiology, 166, 3340772.

Ajzen, I. (1991), "The theory of planned behavior", Organizational Behavior and Human Decision Processes, Vol. 50 No. 2, pp. 179-221. 
Al-Nahdi, T.S.M.B.B. (2008), "Intention to patronage halal restaurants among Malaysian Muslims: an issue of halal perception", Master Thesis USM.

Bananuka, J., Kasera, M., Muganga, G. N., Musimenta, D., Ssekiziyivu, B., \& Kimuli, S. N. L. (2019). Attitude: mediator of subjective norm, religiosity and intention to adopt Islamic banking. Journal of Islamic Marketing.

Borzooei, M., \& Asgari, M. (2014). The effect of religious commitment on Halal brand relationship and purchase intention. The International Journal's Research Journal of Economics and Business Studies, 3(4), 14-19.

Dodds, W. B.,Monroe, K. B. and Grewal, D. (1991), "Effects of price, brand, and store information on buyers' product evaluations". Journal of Marketing Research, Vol. 28, No. 3, pp. 307-319.

Elseidi, R. I. (2018). Determinants of halal purchasing intentions: evidences from UK. Journal of Islamic Marketing, 9(1), 167-190.

Erkan, I. and Evans, C. (2016), "The influence of eWOM in social media on consumers' purchase intentions: an extended approach to information adoption", Computers in Human Behavior, Vol. 61 No. 11, pp. 47-55.

Fishbein, M.A. and Ajzen, I. (1975), Belief, Attitude, Intention and Behaviour: An Introduction to Theory and Research, Addison-Wesley, Reading, MA.

Garg, P., \& Joshi, R. (2018). Purchase intention of "Halal" brands in India: the mediating effect of attitude. Journal of Islamic Marketing, 9(3), 683-694.

Garson, G. D. (2016). Partial Least Squares: Regression \& Structural Equation Models. Statistical Associates Publishing.

Hair, J. F., Ringle, C. M., \& Sarstedt, M. (2011). PLS-SEM: Indeed a silver bullet. Journal of Marketing theory and Practice, 19(2), 139-152.

Henning-Thurau, T., Gwinner, K.P., Walsh, G. and Gremler, D.D. (2004), "Electronic wordof-mouth via customer opinion platform: what motivates consumers to articulate themselves on the internet", Journal of Interactive Marketing, Vol. 18 No. 1, pp. 3852.

Hussein, A. S. (2015). Penelitian Bisnis dan Manajemen Menggunakan Partial Least Square (PLS) dengan smartPLS 3.0. Universitas Brawijaya.

Jalilvand, M. R., \& Samiei, N. (2012). The impact of electronic word of mouth on a tourism destination choice: Testing the theory of planned behavior (TPB). Internet Research: Electronic Networking Applications and Policy, 22(5), 591-612.

K. Byon, K., Lee, S., \& A. Baker, T. (2014). A cross-cultural study of purchase intention of sponsored products based on American and Korean spectators of the 2010 FIFA World Cup South Africa. Sport, Business and Management: An International Journal, 4(2), 158-177.

Keller, K.L. and Lehmann, D.R. (2006), “ Brands and branding: research findings and future priorities", Marketing Science, Vol. 25 No. 6, pp. 740-759.

Khan, A. and Azam, M.K. (2016), "Factors affecting halal product purchase intention in India: preliminary investigation", The IUP Journal of Marketing Management, Vol. 15 No. 1.

Kudeshia, C., \& Kumar, A. (2017). Social eWOM: does it affect the brand attitude and purchase intention of brands?. Management Research Review, 40(3), 310-330.

Lopez, M. and Sicilia, M. (2014), "eWOM as source of influence: the impact of participation in eWOM and perceived source trustworthiness on decision making", Journal of Interactive Advertising, Vol. 14 No. 2, pp. 86-97.

Lutz, R.J. (1991), "The role of attitude theory in marketing", Perspectives in Consumer Behavior, Prentice-Hall, Englewood Cliffs, NJ, pp. 317-339. 
Miniard, P.W. and Cohen, J.B. (1983), "Modeling personal and normative influences on behavior", Journal of Consumer Research, Vol. 10, pp. 169-80.

Mukhtar, A., \& Mohsin Butt, M. (2012). Intention to choose Halal products: the role of religiosity. Journal of Islamic Marketing, 3(2), 108-120.

Park, D.H., Lee, J. and Han, I. (2007), "The effect of on-line consumer reviews on consumer purchasing intention: the moderating role of involvement", International Journal of Electronic Commerce, Vol. 11 No. 4, pp. 125-148.

Paul, J., Modi, A. and Patel, J. (2016), "Predicting green product consumption using theory of planned behavior and reasoned action", Journal of Retailing and Consumer Services, Vol. 29, pp. 123-134.

Pool, J. K., \& Najafabadi, A. H. J. (2015). Developing a model to analyse the effects of brand constructs on word-of-mouth and purchase intention for Halal brands. Journal for Global Business Advancement, 8(3), 342-353.

Poulis, A., Rizomyliotis, I., \& Konstantoulaki, K. (2019). Do firms still need to be social? Firm Generated Content in social media. Information Technology \& People, 32(2), 387-404.

Prendergast, G., Ko, D. and Siu Yin, V.Y. (2010), "Online word of mouth and consumer purchase intentions", International Journal of Advertising, Vol. 29 No. 5, pp. 687708.

Ryan, M.J. (1982), "Behavioral intention formation: the interdependency of attitudinal and social influence variables", Journal of Consumer Research, Vol. 9, pp. 263-77.

Tariq, M. I., Nawaz, M. R., Nawaz, M. M., \& Butt, H. A. (2013). Customer perceptions about branding and purchase intention: a study of FMCG in an emerging market. Journal of Basic and Applied Scientific Research, 3(2), 340-347.

TheJakartaPost. (2019, July 2). thejakartapost.com. Retrieved from F\&B contribution to GDP steadily increases: https://www.thejakartapost.com/news/2019/07/02/fbcontribution-to-gdp-steadily-increases.html

Themba, G. and Mulala, M. (2013), "Brand-related eWOM and its effects on purchase decisions: an empirical study of University of Botswana students", International Journal of Business and Management, Vol. 8 No. 8, p. 31.

Wu, P.C. and Wang, Y.C. (2011), "The influences of electronic word-of-mouth message appeal and message source credibility on brand attitude", Asia Pacific Journal of Marketing and Logistics, Vol. 23 No. 4, pp. 448-472.

Yan, J. (2011), "Social media in branding: fulfilling a need", Journal of Brand Management, Vol. 18 No. 9, pp. 688-696.

Ying, H.L. and Chung, C.M.Y. (2007), "The effects of single-message single-source mixed word-ofmouth on product attitude and purchase intention", Asia Pacific Journal of Marketing, Vol. 19 No. 1, pp. 75-86 